Selected references

1 McGehee, D.S. and Role, L.W. (1995) Annu. Rev. Physiol. 57, 521-546

2 Colquhoun, L.M. and Patrick, J.W. (1997) Adv. Pharmacol. 39, 191-220

3 Ramirez-Latorre, J. et al. (1996) Nature 380, 347-351

4 Wonnacott, S.B. (1997) Trends Neurosci. 20, 92-98

5 Levin, E.D. and Simon, B.B. (1998) Psychopharmacology 138, 217-230

6 James, J.R. and Nordberg, A. (1995) Behav. Genet. 25, 149-159

7 Woolf, N.J. (1991) Prog. Neurobiol. 37, 474-524

8 Whitehouse. P.J. et al. (1982) Science 215, 1237-1239

9 Squire, L.R. and Zola-Morgan, S. (1988) Trends Neurosci. 11, 170-175

10 Eichenbaum, H. et al. (1996) Proc. Natl. Acad. Sci. U. S. A. 93 13500-13507

11 Bear, M.F. (1996) Proc. Natl. Acad. Sci. U. S. A. 93, 13453-13459

12 Frotscher, M. and Léránth, C. (1985) J. Comp. Neurol. 239, 237-246

13 Matthews, D.A. et al. (1987) Brain Res. 402, 30-43

14 Jones, S. and Yakel, J.L. (1997) J. Physiol. 504, 603-610

15 Alkondon, M. et al. (1997) J. Pharmacol. Exp. Ther. 283, 1396-1411

16 Frazier, C.J. et al. (1998) J. Neurosci. 18, 1187-1195

17 McQuiston, A.R. and Madison, D.V. (1999) J. Neurosci. 19 2887-2896

18 Frazier, C.J. et al. (1998) J. Neurosci. 18, 8228-8235

19 Gray, R. et al. (1996) Nature 383, 713-716

20 Jones, S. and Yakel, J.L. (1999) Cell Biochem. Biophys. 31, 47-58

21 Stewart, M. and Fox, S.E. (1990) Trends Neurosci. 13, 163-169

22 Fisahn, A. et al. (1998) Nature 394, 186-189

23 Cobb, S.R. et al. (1999) J. Physiol. 518, 131-140

24 Yamamoto, J. (1998) Eur. J. Pharmacol. 359, 131-133

25 Alkondon, M., Pereira, E.F.R. and Albuquerque, E.X. (1998) Brain Res. 810, 257-263

26 Alkondon, M. et al. (1999) J. Neurosci. 19, 2693-2705

27 Roerig, B., Nelson, D.A. and Katz, L.C. (1997) J. Neurosci. 17, 8353-8362

28 Xiang, Z., Huguenard, J.R. and Prince, D.A. (1998) Science 281, 985-988

29 Sudweeks, S. and Yakel, J.L. (1999) Soc. Neurosci. Abstr. 25, 2241

30 Picciotto, M.R. et al. (1995) Nature 374, 65-67

31 Lu, Y. et al. (1998) J. Pharmacol. Exp. Ther. 287, 648-657

32 Gil, Z., Connors, B.W. and Amitai, Y. (1997) Neuron 19, 679-686

33 Vidal, C. and Changeaux, J-P. (1993) Neuroscience 56, 23-32

34 Bliss, T.V.P. and Collingridge, G.L. (1993) Nature 361, 31-39

35 Hunter, B.E. et al. (1994) Neurosci. Lett. 168, 130-134
36 McNaughton, B.L. and Morris, R.G.M. (1987) Trends Neurosci. $10,408-415$

37 Role, L.W. and Berg, D.K. (1996) Neuron 16, 1077-1085

38 Zheng, J.O. et al. (1994) Nature 368, 140-144

39 Bear, M.F., Carnes, K.M. and Ebner, F.F. (1985) J. Comp. Neurol. $237,519-532$

40 McDonald, J.K., Speciale, S.G. and Parnavelas, J.G. (1987) Neuroscience 21, 825-832

41 Henderson, Z. (1991) Neuroscience 44, 331-324

42 Robertson, R.T. et al. (1991) Dev. Brain Res. 58, 81-95

43 Kristt, D.A. (1979) J. Comp. Neurol. 186, 1-15

44 Bear, M.F. and Singer, W. (1986) Nature 320, 172-176

45 Sato, H. et al. (1987) J. Neurophysiol. 58, 765-780

46 Gu, Q. and Singer, W. (1993) Eur. J. Neurosci. 5, 475-485

47 Fuchs, J.L. (1989) Brain Res. 501, 223-234

48 Broide, R.S. et al. (1995) Neuroscience 67, 83-94

49 Aramakis, V.B. and Metherate, R. (1998) J. Neurosci. 18 8485-8495

50 Robinson, T.E. and Berridge, K.C. (1993) Brain Res. Rev. 18, 247-291

51 Kalivas, P.W. and Stewart, J. (1991) Brain Res. Rev. 16, 223-244

52 Stolerman, I.P. and Shoaib, M. (1991) Trends Pharmacol. Sci. 12, 467-473

53 Corrigall, W.A. (1991) Br. J. Addiction 86, 507-510

54 Corrigall, W.A. et al. (1992) Psychopharmacology 107, 285-289

55 Nisell, M., Nomikos, G.G. and Svensson, T.H. (1995) Pharmacol. Toxicol. 76, 157-162

56 Nisell, M., Nomikos, G.G. and Svensson, T.H. (1994) Pharmacol. Toxicol. 75, 348-352

57 Nisell, M., Nomikos, G.G. and Svensson, T.H. (1994) Synapse 16, $36-44$

58 Yeomans, J.S. (1995) Neuropsychopharmacology 12, 3-16

59 Blaha, C.D. (1996) J. Neurosci. 16, 714-722

60 Futami, T., Takakusaki, K. and Kitai, S.T. (1995) Neurosci. Res. $21,331-342$

61 Grenhoff, J., Aston-Jones, G. and Svensson, T.H. (1986) Acta. Physiol. Scand. 128, 351-358

62 Wonnacott, S. (1990) Trends Pharmacol. Sci. 11, 216-219

63 Dani, J.A. and Heinemann, S. (1996) Neuron 16, 905-908

64 Calabresi, P., Lacey, M.G. and North, R.A. (1989) Br. J. Pharmacol. 98, 135-140

65 Pidoplichko, V.I. et al. (1997) Nature 390, 401-404

66 Picciotto, M.R. et al. (1998) Nature 391, 173-177

67 Shoaib, M. et al. (1994) Br. J. Pharmacol. 111, 1073-1080

68 Schilstrom, B. et al. (1998) Neuroscience 82, 781-789

69 Wolf, M.E. (1998) Prog. Neurobiol. 54, 679-720
Acknowledgements The authors thank D.L. Armstrong, D. Pettit and S.D. Bryant for their insightful comments on this manuscript.

\title{
Long-term potentiation in the amygdala: a mechanism for emotional learning and memory
}

\author{
Stephen Maren
}

In the mammalian brain, LTP is an enduring form of synaptic plasticity that is posited to have a role in learning and memory. Compelling new evidence for this view derives from studies of LTP in the amygdala, a brain structure that is essential for simple forms of emotional learning and memory, such as Pavlovian fear conditioning in rats. More specifically, antagonists of the NMDA receptor block both amygdaloid LTP induction and fear conditioning, fear conditioning induces increases in amygdaloid synaptic transmission that resemble LTP, and genetic modifications that disrupt amygdaloid LTP eliminate fear conditioning. Collectively, these results provide the mostconvincing evidence to date that LTP mediates learning and memory in mammals.

Trends Neurosci. (1999) 22, 561-567

Prat

HE CAPACITY to learn that some events in the world have adverse consequences is not only practical, but is also adaptive: individuals that cannot learn to recognize threats in the environment are doomed to injury and death. Pavlovian fear conditioning is a simple form of associative learning that supports the acquisition of this type of information. Simply stated, fear conditioning occurs when an innocuous stimulus (the conditional
Stephen Maren is at the Dept of Psychology and Neuroscience Program, University of Michigan, MI 48109-1109, USA. 
A

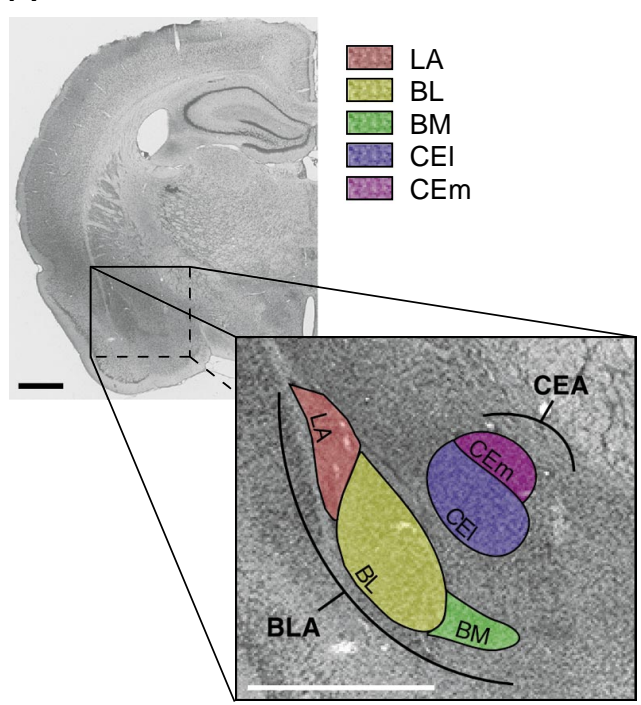

B

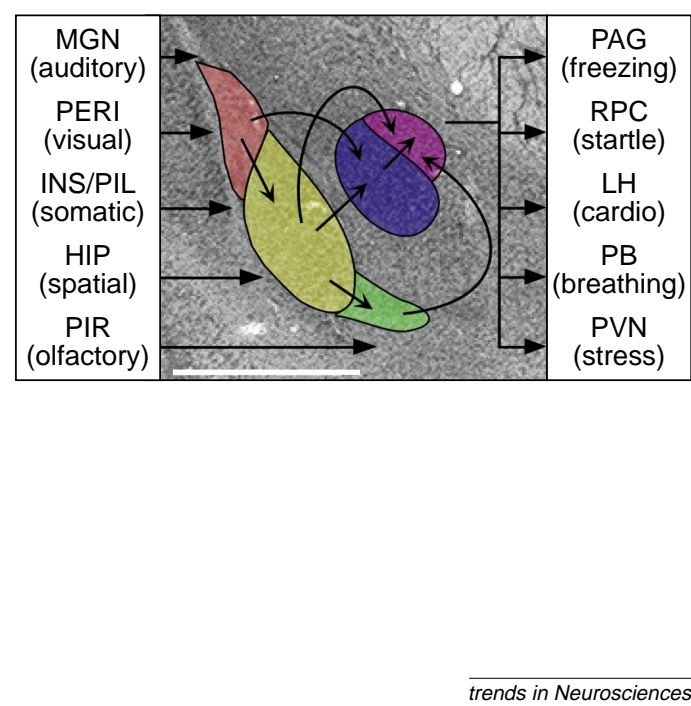

Fig. 1. Anatomy and connectivity of fear-conditioning circuits in the rat amygdala. As shown in the thionin-stained coronal section (A), and enlarged in the inset, the amygdala is a complex of nuclei located deep within the temporal lobe. The colored overlays highlight the amygdaloid nuclei known to be important in fear conditioning. These include the lateral (LA), basolateral (BL) and basomedial (BM) nuclei, which together form the basolateral complex (BLA), and the central nucleus, CEA (CEm, medial and CEl, lateral). The BLA receives and integrates sensory information from a variety of sources [arrows in (B)], including the thalamic medial geniculate nucleus (MGN, auditory), the perirhinal cortex (PERI, visual), the insular cortex (INS, gustatory and somatosensory), the thalamic posterior intralaminar nucleus (PIL, somatosensory), the hippocampal formation (HIP, spatial and contextual) and piriform cortex (PIR, olfactory). Thus, the $B L A$ is a locus of sensory convergence and a site for conditional stimulus-unconditional stimulus (CS-US) association within the amygdala. Intra-amygdaloid circuitry conveys the CS-US association to the CEA, where divergent projections to the hypothalamus and brainstem mediate fear responses such as freezing (periaqueductal gray, PAG), potentiated acoustic startle (nucleus reticularis pontis caudalis, RPC), increased heart rate and blood pressure (lateral hypothalamus, $L H$ ), increased respiration (parabrachial nucleus, $P B$ ) and glucocorticoid release (paraventricular nucleus of the hypothalamus, PVN). Scale bars, $1 \mathrm{~mm}$.

stimulus or CS) precedes the occurrence of a different, aversive stimulus (the unconditional stimulus or US). In rats, pairing a neutral CS, such as a loud tone, with an aversive US, such as an electric footshock, generates fear conditioning. After a few trials, the CS eventually elicits robust conditional fear responses (CRs), which include potentiated acoustic startle, hypoalgesia, elevated blood pressure and freezing (immobility except for breathing). Fear conditioning is acquired rapidly, retained over long periods of time, and is readily studied in both rats and humans. Indeed, the ease of establishing and assessing fear memories has established fear conditioning as a popular learning task for behavioral, biochemical and molecular studies of learning and memory.

Because of the relevance of fear conditioning to disorders of fear and anxiety in humans, a major goal of research has been to identify the crucial brain substrates and neuronal mechanisms that underlie Pavlovian fear conditioning in rats. After years of research, there is almost unanimous agreement that the amygdala, a nutshaped structure that lies deep within the temporal lobes, is essential for forming and storing fear memories ${ }^{1-4}$. The identification of an essential basis for fear conditioning has now opened the door to studies of synaptic and molecular processes within the amygdala that underlie this form of learning. One candidate cellular mechanism for amygdala-dependent learning is LTP, an enduring form of synaptic plasticity that was discovered in the hippocampus and has recently been identified in the amygdala. In this article, the compelling new evidence that implicates amygdaloid LTP in fear conditioning will be described, and the possibility that synaptic

potentiation in the amygdala is a mechanism for emotional learning and memory will be discussed. The focus on fear conditioning in this article should not overshadow the other roles posited for the amygdala, such as the modulation of declarative memory consolidation ${ }^{5}$ and attention ${ }^{6}$.

\section{Neural circuitry of fear conditioning}

It has been recognized for decades that the amygdala is involved in emotional processes ${ }^{7}$, including aversively motivated learning ${ }^{8,9}$ (see Ref. 10 for an excellent review of amygdaloid anatomy). The major amygdaloid nuclei and projections are shown in Fig. 1. Recent anatomical and behavioral evidence indicates that there are at least two distinct subsystems within the amygdala that are important for Pavlovian fear conditioning ${ }^{11,12}$. The first subsystem of the amygdala consists of the lateral, basolateral and basomedial nuclei. These nuclei, which are collectively referred to as the basolateral amygdaloid complex (BLA), form the primary sensory interface of the amygdala. Thus, the BLA receives synaptic input from many primary sensory structures, and lesions in these structures yield deficits in Pavlovian fear conditioning. For example, projections from the auditory thalamus and auditory cortex to the BLA are essential for conditioning to auditory CSs (Refs 13-15), projections from the hippocampal formation to the BLA appear to underlie conditioning to contextual CSs (Refs 16-18), and projections from the perirhinal cortex transmit visual CS information to the BLA (Ref. 19). Information about the aversive footshock US might reach the BLA via parallel thalamic and cortical pathways ${ }^{20}$. Consistent with this anatomy, single neurons in the BLA respond to auditory, visual and somatic (shock) stimuli, which indicates that the amygdala is a locus of convergence for information about CSs and USs (Ref. 21). The BLA is, therefore, anatomically situated to integrate information from a variety of sensory domains.

The information processed by the BLA is either relayed back to afferent structures or sent to the second major subsystem of the amygdala, the central nucleus of the amygdala (CEA). The CEA projects to many brainstem targets and is the amygdala's interface with the fearresponse systems. For example, the CEA projects to the nuclei in the hypothalamus, midbrain and medulla that control a variety of defensive responses, including freezing and acoustic startle. Electrical stimulation of the CEA produces responses that are similar to those elicited by stimuli paired with shock ${ }^{22,23}$, and lesions of the CEA also produce profound deficits in both the acquisition and expression of conditional fear ${ }^{24,25}$. Moreover, lesions placed in structures that are efferent to the CEA, such as the lateral hypothalamus or periaqueductal grey (PAG), produce selective deficits in either cardiovascular or somatic conditional fear responses, respectively ${ }^{26}$. This 
suggests that the CEA is the final common pathway for the generation of learned fear responses. Thus, the amygdala contains two distinct subsystems that represent areas of either sensory convergence (BLA) or response divergence (CEA).

\section{Fear memories are formed and} stored in the basolateral amygdala

Much evidence indicates that the BLA is the crucial neural locus for the formation and storage of fear memories. Selective lesions of the BLA abolish both acquisition and expression of conditional fear in several behavioral paradigms ${ }^{27,28}$. In addition, BLA lesions yield deficits in conditional fear when they are made up to one month after training ${ }^{29,30}$ or after extensive overtraining $^{31}$. Similar to permanent lesions, manipulations that temporarily disable amygdaloid neurons prevent both the acquisition and expression of fear conditioning ${ }^{32,33}$. Fearconditioning deficits are associative in nature, because rats with BLA lesions can perform the freezing response under some conditions ${ }^{34}$. Consistent with this, reversible inactivation of the BLA during training produces learning deficits that are manifest during testing with an intact amygdala ${ }^{32,33}$.

The view that the BLA is a locus of plasticity during aversive learning is further supported by electrophysiological studies of neuronal activity in the amygdala during auditory fear conditioning. For example, neurons in the amygdala exhibit short-latency, CS-elicited firing during aversive learning ${ }^{35-37}$. Associative neuronal firing in the BLA precedes the development of both behavioral CRs and associative firing in other brain structures, including the auditory cortex ${ }^{38}$. Moreover, an intact amygdala is required for the acquisition of at least some forms of neuronal plasticity in the auditory cortex ${ }^{39}$. Because of its essential role in forming and storing fear memories, the BLA serves as an ideal anatomical substrate for analyzing the relationship of synaptic plasticity mechanisms, such as LTP, to behavior ${ }^{12,40}$.

\section{Amygdaloid neurons exhibit LTP}

The first examination of synaptic plasticity in the amygdala was performed by Racine and colleagues in awake, behaving rats. In this preparation, 'tetanic' LTP (which is contrasted with 'behavioral' LTP) was induced in the amygdala by applying high-frequency electrical stimulation to the pyriform cortex ${ }^{41}$. This LTP consisted of a long-term enhancement in the amplitude of stimulus-elicited extracellular field potentials recorded in the amygdala. More recently, tetanic LTP has been reported in both thalamo-amygdala and hippocampoamygdala projections in vivo $o^{42-44}$ : Fig. 2 illustrates the latter. Both of these pathways are believed to transmit CS information to BLA neurons, and potentiation of thalamo-amygdaloid synapses enhances the amplitude of auditory-stimulus-elicited potentials in the BLA
B
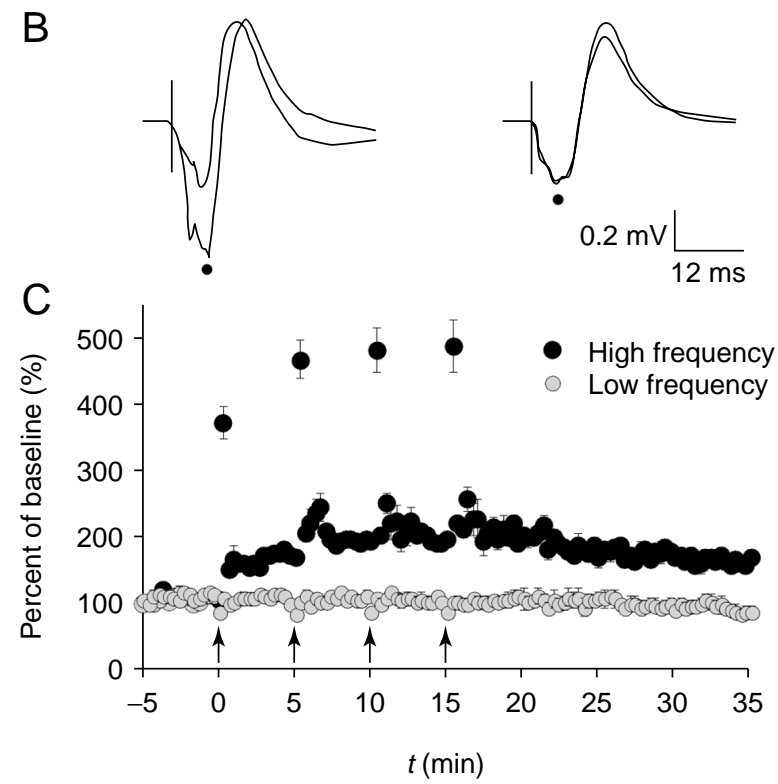

(Ref. 44). Studies using intracellular recording in amygdala slices have confirmed that BLA neurons exhibit tetanic LTP in vitro ${ }^{45}$.

As in the hippocampus ${ }^{46,47}$, LTP induction in the BLA has been reported to require the activation of NMDA receptors $^{42,48,49}$. However, there are indications that LTP induction in the amygdala does not require NMDAreceptor activation under some conditions ${ }^{48,50}$. In fact, LTP induction on amygdaloid interneurons appears to be mediated by $\mathrm{Ca}^{2+}$-permeable AMPA receptors, rather than NMDA receptors ${ }^{51}$. This suggests that there are both NMDA-receptor-dependent and NMDA-receptorindependent forms of LTP in the amygdala. Once induced, the mechanisms involved in expressing amygdaloid LTP are not fully understood. There is evidence for increased presynaptic neurotransmitter release following LTP induction in the amygdala (that is, pairedpulse facilitation in the BLA is attenuated following LTP induction $)^{42,48}$, although changes in the properties of postsynaptic AMPA receptors cannot be ruled out ${ }^{42}$. It should also be noted that BLA neurons also exhibit LTD of synaptic transmission under some conditions and metabotropic glutamate receptors appear to regulate the induction of this form of plasticity ${ }^{52}$. Although not yet tested, LTD at synapses in the amygdala might also be involved in fear conditioning, particularly with regard to the acquisition of inhibitory associations.

\section{Glutamate receptors in the amygdala are essential for fear conditioning}

The important role for glutamate receptors in amygdaloid LTP suggests a role for these receptors in the acquisition and expression of Pavlovian fear conditioning. Consistent with this view, several laboratories have now demonstrated that the infusion of NMDA-receptor antagonists, such as ( \pm )-2-amino-5-phosphonovaleric 

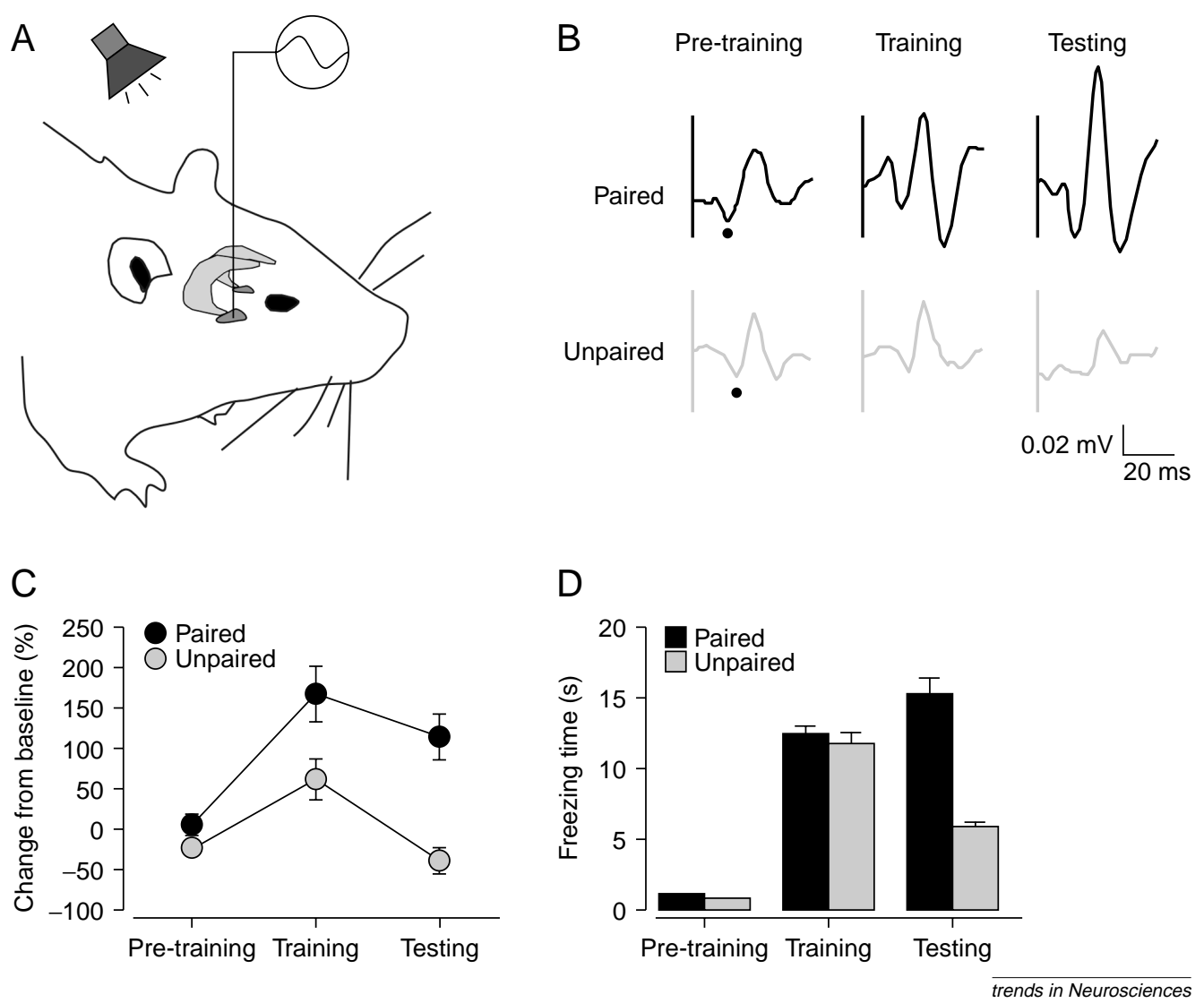

Fig. 3. Behavioral LTP is induced in the lateral nucleus of the amygdala by Pavlovian fear conditioning. A recording electrode was placed in the lateral nucleus of the amygdala ( $L A$, dark gray) to measure auditory-stimulus-elicited extracellular field potentials in awake rats (A). (B) Brief tone stimuli elicited a biphasic extracellular field potential with a shortlatency negative component (pre-training, indicated by the black dots). (C) Pairing the tone stimulus with an aversive footshock (training) potentiated the short-latency negative component, and this potentiation persisted during a shock-free extinction test (testing). Potentiation of the LA field potential did not occur in rats receiving unpaired tones and footshocks. (D) Both paired (black) and unpaired (gray) training generated freezing during the conditioning phase, although paired training induced significantly greater freezing to the tone CS than unpaired training during testing. Adapted, with permission, from Ref. 62.

acid (APV), into the BLA prevents the acquisition of conditional fear responses, including freezing ${ }^{53-55}$ and fear-potentiated startle $e^{56,57}$. Moreover, it has been reported that AMPA-receptor antagonists impair the expression of conditional fear ${ }^{58}$ and that AMPA-receptor agonists enhance the acquisition of fear conditioning ${ }^{59}$. These results reveal an important role for amygdaloid glutamate receptors in the acquisition and expression of fear conditioning.

One unanticipated finding that has emerged from this work is that pre-testing infusions of APV into the amygdala impair the expression of some learned fear responses, such as freezing ${ }^{54,55}$, but leaves others, such as fear-potentiated startle, intact ${ }^{56,57}$. The disruption of conditional freezing might be explained, at least in part, by the observation that APV reduces cell excitability at some synapses in the amygdala in vivo ${ }^{42,60}$. Moreover, it is possible that conditional fear responses, such as freezing and fear-potentiated startle, are under the control of two different populations of amygdaloid neurons that differ in their levels of NMDA receptors ${ }^{54}$. Doublelabeling studies that have examined NMDA-receptor binding in neurons in the amygdala that project to the PAG and nucleus reticularis pontis caudalis (RPC), which control freezing and startle responses, respectively, would be useful for investigating this possibility. Even so, the similar effects of APV on both the acquisition and expression of conditional freezing is problem- atic for linking amygdaloid NMDA receptors to fear conditioning, insofar as NMDA receptors are only thought to have a role in encoding, not retrieving, fear memories. One might be tempted to conclude that NMDA-receptor antagonists exert their action on fear conditioning through a reduction in amygdaloid cell excitability, rather than a disruption of LTP induction. While this might be true for conditional freezing, the selective effect of intraamygdala administration of APV on the acquisition of fear-potentiated startle, as opposed to the expression, suggests that APV retards fear conditioning through an attenuation of amygdaloid LTP rather than a reduction in cell excitability ${ }^{61}$

\section{Fear conditioning induces LTP in the amygdala}

The ability of NMDA-receptor antagonists to block both the induction of tetanic LTP in the amygdala and the acquisition of fear conditioning suggests that a process akin to tetanic LTP might underlie the acquisition of conditional fear in awake, behaving rats. Two recent studies are consistent with this possibility. In the first study, LeDoux and colleagues found that fear conditioning in response to an auditory CS enhanced auditory-elicited potentials in the BLA in a manner that was similar to that observed following the induction of tetanic LTP in auditory projections to the BLA (see Fig. 3$)^{62}$. In other words, both behavioral learning and high-frequency electrical stimulation enhanced the amplitude of extracellular auditory-stimulus-elicited field potentials in the amygdala. The similar potentiation of auditory-stimuluselicited field potentials by high-frequency stimulation and behavioral learning suggests that LTP in auditory pathways to the amygdala might in fact mediate fear conditioning to an auditory CS.

The second study that has examined the relationship between behavioral learning and amygdaloid LTP used a different approach. McKernan and colleagues first trained rats in a fear-potentiated startle paradigm and then sacrificed the animals in order to obtain intracellular recordings from amygdaloid neurons in brain slices ${ }^{63}$. One advantage of this preparation is that the investigators could examine pharmacologically characterized synaptic currents in single amygdaloid neurons. These investigators found that prior fear conditioning selectively enhanced excitatory AMPAreceptor-mediated synaptic currents in thalamic projections to BLA neurons, but not in projections from the endopyriform nucleus. AMPA-receptor-mediated currents were not enhanced in rats that received unpaired tones and footshocks (a control procedure for the nonassociative effects of tone and footshock). NMDAreceptor-mediated currents were not potentiated under any circumstances. These data indicate that associative 
learning in a fear-conditioning paradigm can produce a selective augmentation of excitatory synaptic transmission in auditory projections to the amygdala.

McKernan and colleagues provided some clues to the nature of the synaptic modification that underlies the enhanced AMPA-receptormediated currents in BLA neurons with an analysis of paired-pulse facilitation of excitatory synaptic currents recorded from amygdaloid neurons ${ }^{63}$. As has been reported following the induction of tetanic LTP in the amygdala ${ }^{42,48}$, rats that underwent paired training exhibited reduced paired-pulse facilitation ${ }^{63}$. This suggests that both behavioral LTP and tetanic LTP are associated with increases in neurotransmitter release, insofar as manipulations that increase neurotransmitter release (such as decreasing the extracellular $\left[\mathrm{Mg}^{2+}\right] /\left[\mathrm{Ca}^{2+}\right]$ ratio) also reduce paired-pulse facilitation. Pairedpulse facilitation is not attenuated in endopyriform projections to BLA neurons.

Taken together, this pair of studies $^{62,63}$ indicates that fear conditioning induces behavioral LTP in the amygdala. This outcome was apparent whether synaptic responses were measured 'on-line' in the awake, behaving rat ${ }^{62}$ or 'off-line' in amygdala slices obtained from previously conditioned rats ${ }^{63}$. In both preparations, behavioral LTP exhibited properties that were common to tetanic LTP. For example, both behavioral and tetanic LTP were manifest in enhanced auditory-stimulus-elicited potentials in vivo, and reduced paired-pulse facilitation in vitro. Although it has not yet been examined, an important issue concerns the NMDA-receptor dependency of behavioral LTP in these preparations. A similar dependency of both behavioral LTP induction and fear conditioning on NMDA-receptor activation would provide further support for the involvement of amygdaloid LTP in the acquisition of fear memories.

\section{Molecular basis of amygdaloid LTP and fear conditioning}

A novel and exciting approach to examining the relationship between synaptic plasticity mechanisms, and learning and memory involves the use of genetically modified animals. In the past few years, many mice have been engineered with genetic manipulations that either disable or eliminate key proteins in the intracellular biochemical cascades that mediate LTP. While these studies have largely focused on the relationship of hippocampal LTP to behavior, several recent investigations using genetically modified mice have probed the link between amygdaloid LTP and Pavlovian fear conditioning.

Indirect evidence for a role for amygdaloid LTP in fear conditioning has come from the work of Kandel and colleagues who used mice that overexpressed a mutant
B

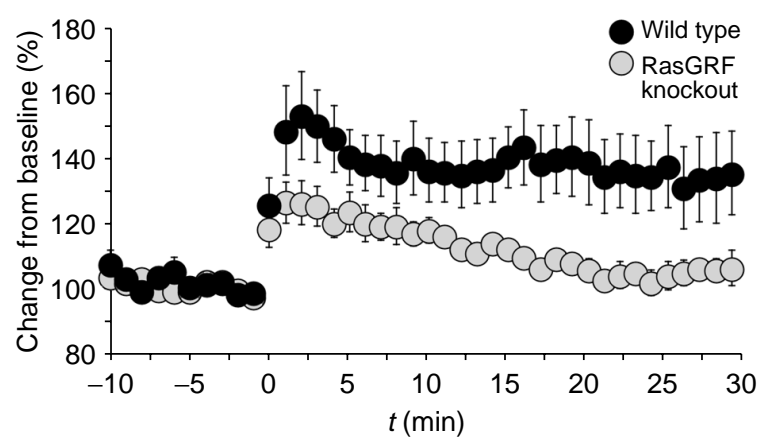

C
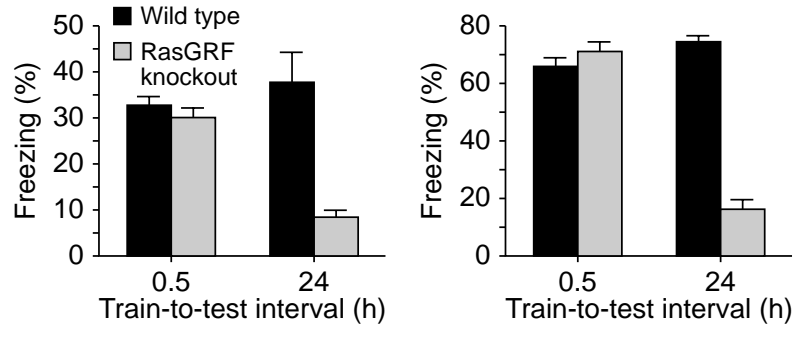

trends in Neurosciences in and Pavlovian fear conditioning.
in blices obtained from wild-type Tetanic LTP in the basolateral nucleus of the amygdala $(B L)$ was characterized in vitro in brain slices obtained from wild-type
mice and mice lacking RasGRF. Extracellular field potentials in $B L$ were elicited by electrical stimulation of the lateral nucleus of the amygdala (LA) (A). High-frequency stimulation of LA induced a robust LTP of synaptic transmission in the BL of wildthe deficit in tetanic LTP in the amygdala, mice lacking RasGRF exhibited deficits in long-term retention of Pavlovian fear 列 the deficit in long-term retention in mice lacking RasGRF was not the result of an inability of these mice to exhibit freezing behavior. Hippocampal LTP in RasGRF knockouts was normal (data not shown). Scale bar, $1 \mathrm{~mm}$. Adapted, with

form of the gene for $\mathrm{Ca}^{2+} /$ calmodulin-dependent protein kinase II (CaMKII) in the amygdala, hippocampus and striatum ${ }^{64}$. In the hippocampus, CaMKII is activated by $\mathrm{Ca}^{2+}$ influx through the NMDA receptor. This kinase interacts with a number of substrates including the cAMP-response-element-binding protein (CREB), a nuclear transcription factor that has been implicated in learning and memory. Not surprisingly, CaMKII has been demonstrated to have a role in LTP induction, and mice that overexpress the transgene for this protein do not exhibit LTP in the hippocampus following thetafrequency stimulation, for example ${ }^{65}$. Interestingly, these transgenic mice, as well as mice that lack CaMKII, also exhibit impairments in Pavlovian fear conditioning to both contextual and auditory cues ${ }^{64,66}$. A similar pattern has been observed in mice with a targeted disruption of CREB, which has been implicated in hippocampal LTP (Ref. 67), and whose synthesis is induced in both the amygdala and hippocampus by fear conditioning ${ }^{68}$. The global impairment in conditional fear to both contextual and auditory cues suggests the existence of amygdala dysfunction in these genetically modified mice. Although the nature of this dysfunction is not yet known, it is tempting to speculate that it will take the form of impaired amygdaloid LTP.

A more-direct demonstration of the role for amygdaloid LTP in fear conditioning comes from studies of mice that lack RasGRF, a neuron-specific guanine nucleotide releasing factor that is activated by both $\mathrm{Ca}^{2+}$ and G-protein-coupled messengers ${ }^{69}$. As shown in Fig. 4, electrophysiological recordings from brain slices 
obtained from such mice reveal a pronounced deficit in LTP in the basolateral nucleus of the amygdala. Interestingly, these mice also exhibit impairments in consolidating long-term memories for Pavlovian fear conditioning to both contextual and acoustic stimuli (see Fig. 4). These deficits in LTP and learning were selective for the amygdala and Pavlovian fear conditioning insofar as both hippocampal LTP and spatial learning in RasGRF knockouts were normal. Interestingly, RasGRF modulates CREB activity through the mitogenactivated protein kinase (MAPK) pathway. A role for MAPK in fear conditioning has recently been demonstrated $^{70}$. Together, these results provide strong support for the view that synaptic LTP in the amygdala is required for the establishment and maintenance of emotional memories.

\section{Associative LTP as a mechanism for Pavlovian fear conditioning}

If LTP in the amygdala is a synaptic mechanism for the acquisition of conditional fear, then it is of interest to consider how such a mechanism might operate during learning. In the hippocampus, tetanic LTP exhibits a property known as associativity (for example, see Ref. 71). Thus, LTP can be induced in 'weak' synaptic pathways if activity in these pathways is paired with activity in a 'strong' pathway. This associative property of LTP can accommodate CS-US association formation in the amygdala during Pavlovian fear conditioning 4,40,72. For example, in the conditional freezing paradigm, an auditory cue does not strongly activate amygdaloid neurons ${ }^{38}$ and, therefore, does not elicit freezing prior to fear conditioning. In contrast, we assume that the footshock US strongly activates amygdaloid neurons to produce a central fear state. Paradoxically, activation of the amygdala by shock USs does not translate into a freezing response. This is believed to be true because the footshock US also activates the dorsal PAG, which results in both the shock-elicited activity burst and inhibition of the ventral PAG, an essential structure for generating the freezing response. During fear conditioning, however, activity in the 'weak' CS pathway is paired with depolarization generated by the 'strong' US pathway. Thus, it is through the temporal association of the CS and US that synapses in the CS pathway are potentiated, presumably through a mechanism akin to associative LTP. Although this mechanism appears plausible, further studies are required to determine whether amygdaloid neurons exhibit associative LTP.

Of course, such a simple model cannot account for the richness of learning phenomena in Pavlovian paradigms by itself. Indeed, several investigators have raised doubts about the heuristic value of using LTP as a model for learning and memory ${ }^{73-75}$. One argument that has been proposed is that the temporal requirements for associative LTP induction are not congruent with optimal Pavlovian-conditioning parameters. However, in cases where there is divergence in the optimal-stimulus timing parameters for LTP induction and fear conditioning, such as in long-delay fear conditioning, one can certainly imagine mechanisms in the brain that reunite temporally discontiguous events under conditions that will favor associative LTP. In fact, Brown and colleagues ${ }^{76}$ recently proposed a computational model that bridges the long CS-US delays that are typically used in fearconditioning experiments. Their model is based on the discovery of late-firing neurons ${ }^{77}$ (neurons that withhold firing an action potential for up to several seconds following injection of a depolarizing current) in the perirhinal cortex, a putative CS pathway to the amygdala. In the model, these late-firing neurons maintain CSelicited firing during the CS-US delay interval so that the CS and US can be instantiated as contiguous events by amygdala neurons using standard Hebbian modification rules. Thus, associative LTP in the amygdala remains a plausible mechanism for fear conditioning, despite the parametric differences between conditioning parameters and optimal LTP induction parameters. This work reveals that an understanding of the computational properties of amygdaloid circuits provides an important insight into the role synaptic plasticity has in the acquisition of emotional learning and memory.

\section{Concluding remarks}

An abundance of evidence indicates that neurons in the amygdala are essential for simple forms of emotional learning and memory, such as Pavlovian fear conditioning in rats. In the amygdala, LTP is an enduring form of synaptic plasticity that has been posited to have a role in Pavlovian fear conditioning. As this article illustrates, this view is supported by compelling new evidence that NMDA-receptor antagonists block both amygdaloid LTP induction and fear conditioning, fear conditioning induces increases in amygdaloid synaptic transmission that resemble LTP, and genetic modifications that eliminate amygdaloid LTP also impair fear conditioning. Collectively, these results provide the strongest evidence to date that LTP mediates learning and memory in mammals.

\section{Selected references}

1 LeDoux, J. (1998) Biol. Psychiatry 44, 1229-1238

2 Davis, M. (1997) J. Neuropsychiatry Clin. Neurosci. 9, 382-402

3 Fanselow, M.S. (1994) Psychonomic Bull. Rev. 1, 429-438

4 Maren, S. (1996) Mol. Neurobiol. 13, 1-22

5 McGaugh, J.L. et al. (1996) Proc. Natl. Acad. Sci. U. S. A. 93, 13508-13514

6 Gallagher, M. and Holland, P.C. (1994) Proc. Natl. Acad. Sci. U. S. A. 91, 11771-11776

7 Kluver, H. and Bucy, P.C. (1937) Am. J. Physiol. 119, 352-353

8 Brady, J.V. et al. (1954) J. Comp. Physiol. Psychol. 47, 179-186

9 Kellicutt, M.H. and Schwartzbaum, J.S. (1963) Psychol. Rep. 12, 351-358

10 Swanson, L.W. and Petrovich, G.D. (1998) Trends Neurosci. 21, 323-331

11 LeDoux, J.E. (1995) Annu. Rev. Psych. 46, 209-235

12 Davis, M. et al. (1994) Trends Neurosci. 17, 208-214

13 Campeau, S. and Davis, M. (1995) J. Neurosci. 15, 2312-2327

14 LeDoux, J.E. et al. (1990) J. Neurosci. 10, 1062-1069

15 Romanski, L.M. and LeDoux, J.E. (1992) J. Neurosci. 12, 4501-4509

16 Kim, J.J. and Fanselow, M.S. (1992) Science 256, 675-677

17 Maren, S. et al. (1997) Behav. Brain Res. 88, 261-274

18 Phillips, R.G. and LeDoux, J.E. (1992) Behav. Neurosci. 106 274-285

19 Rosen, J.B. et al. (1992) J. Neurosci. 12, 4624-4633

20 Shi, C. and Davis, M. (1999) J. Neurosci. 19, 420-430

21 Romanski, L.M. et al. (1993) Behav. Neurosci. 107, 444-450

22 Iwata, J. et al. (1987) Brain Res. 418, 183-188

23 Kapp, B.S. et al. (1982) Brain Res. 234, 251-262

24 Hitchcock, J. and Davis, M. (1986) Behav. Neurosci. 100, 11-22

25 Kim, M. and Davis, M. (1993) Behav. Neurosci. 107, 1088-1092

26 LeDoux, J.E. et al. (1988) J. Neurosci. 8, 2517-2529

27 Campeau, S. and Davis, M. (1995) J. Neurosci. 15, 2301-2311

28 Sananes, C.B. and Davis, M. (1992) Behav. Neurosci. 106, 72-80

29 Maren, S. et al. (1996) Behav. Neurosci. 110, 718-726

30 Lee, Y. et al. (1996) Behav. Neurosci. 110, 836-839

31 Maren, S. (1998) J. Neurosci. 18, 3088-3097

32 Muller, J. et al. (1997) Behav. Neurosci. 111, 683-691

33 Helmstetter, F.J. and Bellgowan, P.S. (1994) Behav. Neurosci. 108, 1005-1009

34 Maren, S. (1999) J. Neurosci. 19, 8696-8703

35 Quirk, G.J. et al. (1995) Neuron 15, 1029-1039

36 Maren, S. et al. (1991) Brain Res. 549, 311-316 
37 Pascoe, J.P. and Kapp, B.S. (1985) Behav. Brain Res. 16, 117-133 38 Quirk, G.J. et al. (1997) Neuron 19, 613-624

39 Armony, J.L. et al. (1998) J. Neurosci. 18, 2592-2601

40 Maren, S. and Fanselow, M.S. (1996) Neuron 16, 237-240

41 Racine, R.J. et al. (1983) Brain Res. 260, 217-231

42 Maren, S. and Fanselow, M.S. (1995) J. Neurosci. 15, 7548-7564

43 Clugnet, M.C. and LeDoux, J.E. (1990) J. Neurosci. 10, 2818-2824

44 Rogan, M.T. and LeDoux, J.E. (1995) Neuron 15, 127-136

45 Chapman, P.F. et al. (1990) Synapse 6, 271-278

46 Bliss, T.V.P. and Collingridge, G.L. (1993) Nature 361, 31-39

47 Maren, S. and Baudry, M. (1995) Neurobiol. Learn. Mem. 63, 1-18

48 Huang, Y.Y. and Kandel, E.R. (1998) Neuron 21, 169-178

49 Gean, P.W. et al. (1993) Brain Res. Bull. 31, 7-11

50 Chapman, P.F. and Bellavance, L.L. (1992) Synapse 11, 310-318

51 Mahanty, N.K. and Sah, P. (1998) Nature 394, 683-687

52 Li, H. et al. (1998) J. Neurosci. 18, 1662-1670

53 Fanselow, M.S. et al. (1994) Behav. Neurosci. 108, 235-240

54 Lee, H. and Kim, J.J. (1998) J. Neurosci. 18, 8444-8454

55 Maren, S. et al. (1996) Behav. Neurosci. 110, 1365-1374

56 Campeau, S. et al. (1992) Behav. Neurosci. 106, 569-574

57 Miserendino, M.J. et al. (1990) Nature 345, 716-718

58 Kim, M. et al. (1993) Behav. Neural Biol. 59, 5-8

59 Rogan, M.T. et al. (1997) J. Neurosci. 17, 5928-5935
60 Li, X.F. et al. (1995) Exp. Brain Res. 105, 87-100

61 Gewirtz, J.C. and Davis, M. (1997) Nature 388, 471-474

62 Rogan, M.T. et al. (1997) Nature 390, 604-607

63 McKernan, M.G. and Shinnick-Gallagher, P. (1997) Nature 390, 607-611

64 Mayford, M. et al. (1996) Science 274, 1678-1683

65 Bach, M.E. et al. (1995) Cell 81, 905-915

66 Chen, C. et al. (1994) Science 266, 291-294

67 Bourtchouladze, R. et al. (1994) Cell 79, 59-68

68 Impey, S. et al. (1998) Nat. Neurosci. 1, 595-601

69 Brambilla, R. et al. (1997) Nature 390, 281-286

70 Atkins, C.M. et al. (1998) Nat. Neurosci. 1, 602-608

71 Barrionuevo, G. and Brown, T.H. (1983) Proc. Natl. Acad. Sci. U. S. A. 80, 7347-7351

72 Fanselow, M.S. (1993) Curr. Dir. Psychol. Sci. 2, 152-156

73 Diamond, D.M. and Rose, G.M. (1994) Psychobiology 22, 263-269

74 Gallistel, C.R. (1995) in Brain and Memory: Modulation and Mediation of Neuroplasticity (McGaugh, J.L., Weinberger, N.M. and Lynch, G., eds), pp. 328-337, Oxford University Press

75 Shors, T.J. and Matzel, L.D. (1997) Behav. Brain Sci. 20, 597-634

76 Tieu, K.H. et al. (1999) Psychobiology 27, 1-25

77 Faulkner, B. and Brown, T.H. (1999) J. Comp. Neurol. 411 613-642
Acknowledgements

The author's research was supported by a grant from the National Institute of Mental Health (R29MH57865).

The author thanks two anonymous referees for helpful comments on a previous version of this manuscript.

\section{States of Mind: New Discoveries about How Our Brains Make Us Who We Are}

\author{
edited by Roberta Conlan, John Wiley \& Sons, 1999. £19.95 ( $x+214$ pages) \\ ISBN 0 47I 299634
}

Dissemination is the soul of science. Not only is it even more vital that we inform an increasingly sceptical public about what we are doing, but a sufficient number of teenagers need to be excited by it. I am almost sure that reading the right article at the right time is a life event that seeds some future crucial bias to study the brain rather than rocket science. So any attempt to fire such enthusiasm by individual scientists sometimes, as here in collaboration with educational organizations such as the Dana Alliance, deserves our fullest admiration.

What is the best way to disseminate? The televised Christmas Royal Institution Lectures in the UK have enormous and well-deserved impact. States of Mind arises from a series of lectures given by distinguished neuroscientists in 1997, in the USA. Whether a 'book of the lectures' is actually the best way to disseminate the material to a wider audience is debatable. It represents a tall order for the erstwhile contributors: it is one thing to provide an entertaining and simplified lecture using good visuals, but quite another to consolidate it to the written page. The assiduous copy editor will badger you into clarifying that minor ambiguity into which you are tempted merely to protect yourself from accusations of opting for the simple story. Your scientific colleagues are liable to read the material in a perversely critical way, especially if you have not conveyed their important theory with complete precision or, worse still, you have omitted to cite them altogether. For an editor, the task of knowing which themes to pursue in such a book, and how optimally to harmonize and sequence the varied contributions from several authors, is a major challenge.

States of Mind rises some way to these challenges. The book focuses on the neural and neurochemical basis of behaviour and individual differences. The title is slightly misleading as the major state of mind, viz consciousness, is alluded to only briefly. There is a stimulating exposition of arousal states in a chapter on sleep by Hobson. The distinction between implicit and explicit memory invokes consciousness in two of the chapters. But most of the advances described are most relevant to the unconscious state. Kandel takes a clearly argued reductionist line on the molecular basis of learning by reference to his famous work on Aplysia. However, for novices it must be disconcerting that this relates to the 'wastebasket' category of forms of learning (termed 'non-declarative memory') rather than the exciting 'declarative' memory deficits they have just learned about from the earlier account of the patient, H.M. Thus, the vaunted synthesis of molecular neuroscience with cognitive psychology is not necessarily portrayed in perhaps the most advantageous light. The implications of the reductionist approach to memory seem very clear; it will indeed be exciting if the same basic molecular mechanisms operate in declarative as well as non-declarative memory. However, we will then have to understand the undoubted differences in functioning of such memory systems in other ways; for example at the computational or neural systems levels, if we are to appreciate their adaptive significance. What does come over well in this context is LeDoux's cameo of his excellent popular work': the possible interplay between implicit memory and working-memory systems in emotion is discussed lucidly, for example, alongside the use of 'neuroscience tools' to investigate the amygdala.

However, it would perhaps have been useful to have at least one contribution from a more cognitively orientated neuroscientist. There are many topics in neuropsychology that would have been sure to delight and inform the lay person about states of mind. Such topics might have included 'blindsight', spatial neglect, alien-hand syndrome, utilization behaviour, theory of mind, hallucinations, delusions and phantom limbs, all of which have been been inspirational for a number of eminent neuroscientists and are probably susceptible to chemical modulation, though admittedly cannot yet be explained in terms of molecules.

The neuroendocrinological and neuroimmunological concomitants of stressful states are particularly well emphasized, although in such a concise book there is perhaps a little too much overlap (to the extent that both use a similar figure of the hypothalamic-pituitary axis) in two otherwise complementary chapters by McEwen and Sternberg. They also relate to a general theme of the biological bases of individual differences introduced in moleculargenetic (Hyman), developmental (Kagan) and psychiatric (Jamison) contexts. The latter two have a good balance of scientific, anecdotal and historical material. This is the type of book in which Galen and Byron feature more prominently in the index than Hubel or Bloom, but this is an eminently reasonable stratagem.

Overall, the style of the book is certainly seductive and the reader's hand is gently held by the editor during the introductory 